\title{
EFEITO DO SOMBRAMENTO DE PUPUNHA (Bactris gasipaes) NA CULTURA DO CAFÉ CONILON
}

\author{
Vinicius Agnolette Capelini ${ }^{1}$ \\ Samira Luns Hatum de Almeida ${ }^{2}$ \\ Jorge Tadeu Fim Rosas ${ }^{3}$ \\ Gabriel Dias de Oliveira ${ }^{4}$ \\ Gustavo Soares de Souza ${ }^{5}$ \\ Julião Soares de Souza Lima ${ }^{6}$ \\ Samuel de Assis Silva ${ }^{7}$
}

Resumo: Objetivou-se com este trabalho analisar o comportamento temporal do teor foliar de clorofila, da área foliar especifica e do índice de sólidos solúveis (medido pelo grau brix) de plantas de café conilon cultivadas em sistemas agroflorestais sombreados com pupunha. As medições de teor foliar de clorofila e área foliar específica foram realizados mensalmente enquanto o grau brix foi medido a partir do início da fase fenológica de maturação. As analises estatísticas foram determinadas pelo teste Tukey a $5 \%$ de probabilidade. Regressões múltiplas foram realizadas para analisar o efeito do sistema arborizado sobre qualidade do café. O teor foliar de clorofila e a área foliar específica apresentaram variabilidade temporal, com destaque para a última variável onde a variação foi elevada. O sombreamento não influenciou a maturação dos frutos. À medida que o teor foliar de clorofila e a área foliar específica se elevam, os valores de ${ }^{\circ}$ Brix também aumentam.

Palavras-chave: Coffea canéfora; Qualidade da bebida; Cafeicultura; Regressão múltipla.

\footnotetext{
${ }^{1}$ Agronomia/Universidade Federal do Espírito Santo, Brasil. E-mail: vinicius91ac@hotmail.com.

2 Agronomia/Universidade Federal do Espírito Santo, Brasil. E-mail: samiraluns@hotmail.com.

3 Agronomia/Universidade Federal do Espírito Santo, Brasil. E-mail: jorgetadeufimrosas@hotmail.com.

${ }^{4}$ Agronomia/Universidade Federal do Espírito Santo, Brasil. E-mail: gabriel.dias.oliveira@gmail.com.

5 Instituto Capixaba de Pesquisa, Assistência Técnica e Extensão Rural/Fazenda Experimental Bananal do Norte, Brasil. E-mail: gsdsouza@hotmail.com.

6 Universidade Federal do Espírito Santo, Brasil. E-mail: limajss@yahoo.com.br.

7 Universidade Federal do Espírito Santo, Brasil. E-mail: sasilva@pq.cnpq.br.
} 